Shininess Special Issue, Journal of Design History.

\title{
Introduction: Shininess
}

It is perhaps the quality of objects' surfaces that most clearly establish their presence and our relationship to them. The spatial coherence of a form, its precise colour and texture - such qualities seem comprehensible by sight alone. Other qualities seem to demand visual and tactile engagement. The rich texture of silks, the depth of polished wood, the evenness of enamelled steel make these things hard to look at without wanting to touch them. Light plays in particular ways on these more or less shiny surfaces and enriches our material environment. But shiny stuff is not simply a matter of sensation: the shininess of materials and objects associates them with strong cultural themes and historical epochs, and is markedly paradoxical.

A consequence of the play of light, while apparently a property of objects, shininess can invite sensual engagement, at the same time as its fragility may refuse it. It is the entanglement of this physicality with a range of contingent meanings that piquest the interest of the editors of this Special Issue. Shine implies the inner nature of some objects: people glow with health and in some cultures this is indexed

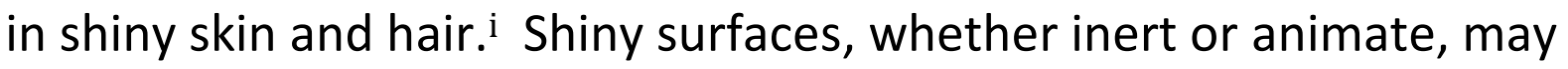
radiate because of effort applied to them and whereas the immanent shine of gold, or skin or hair, may be attractive, the shine of viscous, oily 'slimy' surfaces, which are not clearly solid or liquid, may be repellant, as Sartre noted. ii The shine of one object may strongly connote value while the gloss of another may suggest cheapness and 'glitz'. In a similar way, the 'deep' shine of an old patinated surface speaks of the labour required to produce and maintain it - it requires work and may connote leisure and status while the temporary shininess of many consumer goods aligns precisely with the alleged instability and superficiality of postmodern culture. Shininess then is slippery. We think we know it, but through infinite physical variety and countless cultural contexts its meanings 
become multiple. Shininess appears to have no essence, even though it is a consequence of the physical properties of matter. The articles collected here demonstrate this in the varieties of shininess they relate to - it can be a distinctive property of steel and hair, a metro system and plastic goods. Just as it is a characteristic of matter 'activated' by light, the shininess in these examples is itself activated by culture.

To make sense of the unstable manifestations of shininess, it is perhaps useful to think about the physical properties of matter's interaction with light. Seeking a consistent and specific language for colour, Carole Biggam identified five properties, including 'brightness' alongside 'tone', 'hue', 'saturation' and 'transparency'. She divided brightness into 'light-emission', ranging from 'dazzling' to 'shining-glowing' and 'reflectivity', varying from 'shiny' to 'lustrous-matt. 'iii Her list illustrates the many kinds of reflected light. Such differences in luminosity are the results of fluctuating light (from dim to intense) and diverse reflective materials (from dull to glossy) and encompass the objects and environments of this study. This range of properties is also signalled in the countless descriptive terms used in everyday speech. 'Radiant' surfaces and objects can be glossy or lustrous, gleaming and glowing - emanating inner or reflected light. Given the right physical qualities they may glisten, glint or sparkle. Whether costly or common shiny things shimmer, and given their paradoxical meanings, it is only this instability that seems ever present.

The very language we have for shininess is inherently slippery, as is our perception of it. The ingredients of our experience of shininess point of view, light and materials - are in perpetual flux. Also, human perception is dependent on changing physical and mental circumstances that profoundly affect the ability to know the world. Light, whether natural or manufactured, is equally fleeting, characterised by the perpetual rise and fall of the sun, the constant movement of clouds, and the inevitable deterioration of lighting apparatus. Moreover, the material properties of objects, whether stainless steel, hair, or plastics, also undergo constant change. 
Stainless steel surfaces wear and corrode, hair attracts and releases oils and is treated with conditioners, while the composition of plastic transforms with age. This physical instability is matched by a lack of precision in the language we use for the interaction of surface and light. Marie McGinn describes Wittgenstein's view that in everyday language - 'our ordinary language game' - terms for visual phenomena of all sorts, including describing shininess or colour, are characteristically indeterminate, unstable. ${ }^{\text {iv }}$

Alongside its inherent instability, it is possible to trace relationships between ideas about shininess and the location in time of things, people and culture - ideas about shininess are historically specific. Also, the qualities of surfaces have connotations that imply time itself as well as historical placement in it, because shininess is often fugitive, as well as being time-consuming to achieve. In his essay In Praise of Shadows of 1933, the Japanese novelist, Jun' ichirō Tanizaki celebrated the antique sheen of traditional Japanese interiors in the face of modernity's glare, his poetic language of luminosity elucidating the many meanings of shininess.

Tanizaki's deeply nationalistic meditations powerfully illustrate how specific meanings of shininess are determined by time, practice and locale, 'we [the Japanese] find it hard to be really at home with things that shine and glitter. The Westerner uses silver and steel and nickel tableware, and polishes it to a fine brilliance, but we object to the practice.' The Japanese, Tanizaki asserts, do use silver but do not polish it, 'enjoy[ing]' it only when the 'luster has worn off, when it has begun to take on a dark, smoky patina' or what he later refers to as the 'sheen of antiquity' and 'glow of grime', denoting the patination of touch over many years of handling. ${ }^{v}$ Tanizaki argues that Westerners find beauty in light and 'Orientals' discover beauty in shadows, illustrating the complex and numerous networks of materials, light and human interaction that produce favoured degrees of shadow and light. Tanizaki's view may say more about his own distrust of the march of modernity than perceived national dispositions, 'the progressive Westerner is determined always to better his lot. From candle to oil lamp, oil lamp to gaslight, gaslight to 
electric light-his quest for a brighter light never ceases, he spares no pains to eradicate even the minutest shadow.'vi It is the Westerner's progressiveness that is responsible for the affinity with shininess and light, rather than his 'western-ness' and Tanizaki's comments illuminate the tension between modernity and tradition played out over various shiny surface effects that has its mirror in Western culture.

Grant McCracken's discussion of patinapoints to the relationship between the physical and the cultural - like shininess patina is a 'physical property [...] treated as a symbolic property'. This symbolic significance changes with time and social context but is always rooted in the physicality of the object's surface, it is 'first of all, a physical property and only then a symbolic property'. vii Locating and theorising patina in the context of England and America before and after the eighteenth century, McCracken charts its shift from being a 'mainstay of social organisation' in verifying status to its being supplanted by the modern 'fashion system of consumption' at the end of the eighteenth century. viii

\section{Between tradition and progress}

Specific features of the materiality of shininess and of the discourse it generates can be connected to the concept of modernity. At perhaps the most abstract level, the characteristics of shiny surfaces have particular relationships to the qualities of modern life upon which Baudelaire famously ruminated in 'The Painter of Modern Life', a starting point for many discussions on the culture of modernity. ${ }^{\text {ix }}$ The elements of pre-modern material culture that are 'essentially' shiny - gold, glass, crystal - were also rare; both their shininess and their scarcity conferring value. The maintenance of other pre-modern shiny surfaces - lacquered wood, polished leather - require the application of careful attention and labour. In contrast, modern technological innovation has given us a much larger range of materials that shine - plastics, paints, self-coloured lacquered metals, plate glass and many other luminous compounds - all of which apparently require no labour for them to shine, and which are 
usually quite temporary. Their shine is fleeting, fugitive, fragile characteristically modern according to Baudelaire's formulation of modernity as 'the transitory, the fugitive, the contingent'.

As the discussion below explores, the paradoxes that emerge on considering the significance of shininess in objects and built environments seem to have an innate relationship to the 'double' nature of modernity. Both progressive and unsettling, it is fleeting and 'Janus-faced'. $\mathrm{x}$ Habermas characterises modernity as 'advancing and accelerating historical events' in an active relationship between past and progress. ${ }^{x i}$ This modern dynamic introduced a particular expectation regarding the present that is seen in terms of the future: a modern zeitgeist that implies that this moment is always in the process of being devoured by the next. Thus, in modern consumption the next seems ever shinier than the last. The immanent shine of holy tradition or class hierarchy becomes the glitz of mass consumerism. As Berman observes, after Marx and Baudelaire, along with modernity goes 'de-sanctification' - all that is sacred is profaned. ${ }^{\text {xii }}$

This alignment between temporal shifts in the meaning of shininess and ideas of modern progress can be observed in its symbolic transformations, from pre-modern societies in which it is a carrier of spiritual significance, to modern settings where it is associated with progressive values. Recent academic writing has explored these shifts in meaning within a broader investigation of luminosity and social interaction. In an effort to define an 'anthropology of luminosity' Bille and Søreneson (2007) surveyed the relationship between light, the material world and social action while outlining the notion of 'lightscapes' where light, space, and materials are combined for differing social needs. xiii They identified 'shininess' as a fundamental category, suggesting that 'to fully appreciate the social life of illumination a number of sub-fields of its manifestations are important to consider, such as shadow, shininess and colour.'xiv Most of the shiny lightscapes that Bille and Søreneson list relate to otherworldly values associated with reflective objects, where, for 
example, ancestral presence is evoked through the pre-modern 'glow' of a gleaming artefact.

\section{Labour of Shine: Maintaining and Constituting Identity}

Even in modernity, however, shine is often contingent on labour where the maintenance of an individual's 'extended self' in objects can comprise time-consuming work to preserve the shiny surfaces of their possessions and protect against the effects of wear, corrosion and dirt. The ritualized care for possessions is often the care of shine - the weekly car-wash that preserves a 'show-room' shine, the house carefully prepared for sale presenting its shining tiled and plastic surfaces. These are the 'maintenance rituals' that Grant McCracken identifies through which both the substance and the meanings of objects and possessions are established and confirmed. $\mathrm{xv}$

In his 2010 article Charles Rice shows how the maintenance rituals of boot and shoe shining can constitute domestic subjectivity through the act of caring for - rather than simply cleaning - footwear, e.g. maintaining a shiny surface through manual labour. Through looking at advice books from the late-nineteenth to early-twentieth century he observes that boots and shoes 'emerge as new kinds of objects in households, objects belonging in a group including materially fine furniture and treasured glassware, and they are intrinsic to the new structuring of care.' xvi Rice thus shows how not only a mundane object could rise in status within the constellation of domestic goods, but also how the act of cleaning can be defined as caring and thus relate to pride of ownership in an increasingly servant-less society. . xvii

In parallel, and apparently in contradiction, to this intimate register of caring for the shine of possessions, through the late nineteenth and early twentieth century new shiny materials became available for mass consumption. These were employed to express values associated with modernity including, progress, speed, hygiene and efficiency. In many homes such values were more often materialized in the gleaming taps of kitchens and bathrooms than those of dining and front rooms where the warm sheen of wood furnishings 
predominated. xviii In the first decades of the twentieth century American diners, the iconic roadside restaurants, made great use of sparkling materials in the interiors, including tile, Vitrolite (an opaque coloured glass), Monel Metal (a nickel copper alloy), aluminum and stainless steel, all of which were deployed to indicate clean food and speedy service. ${ }^{x i x}$ After the 1930 s these same structures increasingly employed streamlined stainless steel exteriors, and, along with the 'Airstream' caravan, became prominent symbols of speed and motion.

Long after modernism's rise and fall preservationists would struggle to revive such progressive meanings. In $\mathrm{H}$. Ward Jandl's 'With Heritage so Shiny: America's First All-Aluminum House' the author discusses a project to preserve the Aluminaire, designed by Lawrence Kocher and Albert Frey in 1931. Along with Richard Neutra's Lovell House, built in 1929, the Le Corbusier-inspired, aluminium house was one of the few American homes included in the Museum of Modern Art's International Style: Architecture since 1922 (1932).xx Considered an 'icon of modernism', the house posed a peculiar problem for the architectural conservationists. In order to 'restore the shiny, machine-like quality of the exterior' the original aluminium panels would have to be replaced, thus removing 'authentic' architectural elements the patina of which obscured the meanings favoured by prevailing architectural discourse - their glittering modernity. ${ }^{x x i}$ The semantic role that the fugitive shine of surfaces played in locating objects in competing ideas about what is 'progressive' is evident beyond architecture in the discussions of appropriate principles of design that featured in the Aspen conferences from the late 1940s.

Reyner Banham's contribution to the 1966 conference, 'All that Glitters is not Stainless' is particularly relevant for this special issue. ${ }^{\text {xii }}$ Writing at the dawn of postmodernity he was ideally positioned to comment on the mass production of gleam. Would available shininess erase differences of class and herald a design democracy? Banham seemed to suggest this and more. Here the design critic celebrated a world where those of limited means could access a previously unobtainable universe of gleaming goods. While 
Banham took an anti-elitist stance, attempting to speak for the consuming masses, his contemporaries, such as the architectural critic William H. Jordy, who perhaps represented the audience of design pundits that Banham addressed, decried the proliferation of shiny things. In 1960 Jordy viewed the profusion of glitz as a symptom of a throwaway culture. 'The pervasive consumption ethic of our society with the debauch of novelty inevitably followed by the hangover of obsolescence, encourages a slickness, shininess, and thinness in our buildings. The glittering package of the merchandiser has become the norm for building... Never before have so many buildings so closely approached the metallic wrapped prune box or the automobile bumper...'xxiii Banham's text was surely a retort to such lamentations. For Banham the shiny plastic 'chrome' trim on his Mini became an affirmative symbol of the knowing postmodern consumer.

Speaking to an establishment audience suspicious of glitz, he argued that the pioneers of modernism, including Le Corbusier and Walter Gropius, had significantly embraced and democratized the 'glitter' that modernity made possible, from buildings and cities to works of engineering and the shiny plastics of consumer goods. Ascribing this shimmering modernism to both a fundamental desire of the human heart and the capabilities of modern industry, he noted the paradoxical relationship the design 'establishment' had to it. Pointing to a split between the Pop Art generation and the pioneer modernists, Banham celebrated the former whose '[b]eady little eyes...can tell stainless from spray chrome at fifty paces and prefer the latter because it is more jokey...' suggesting that they favored brilliant irony to the illumination of the soul. ${ }^{x x i v}$ Here Banham holds up the fake shine of faux chrome as more authentic simply for the opportunity it provides for ironic consumption. Banham's twentieth century consumer was no dupe, but a savvy player enjoying a glittering material world. No longer was there a need to demarcate the shiny contemporary universe of things from the black and sooty early modern milieu: both could be enjoyed for their own sake. 
Likewise, Dieter Roelstraete refused to associate shininess with the 'consumerist frenzy of the 1960s commodities boom'. ${ }^{x x v}$ In 'Modernism, Postmodernism and Gleam: On the Photorealist Work Ethic' (2010), he recognized the 'the hyperrealist rendition of shiny, glossy, and glassy surfaces', as central to this new trend in art.xxvi Describing paintings of 'reflecting telephone booths', 'glitzy diners', 'wrapped foodstuffs', and 'flickering skin', Roelstraete refused to identify such obsessively rendered surfaces with Frederic Jameson's notion of postmodern 'depthlessness'. xxvii Jameson used this term when referring to the shimmering towers of late-capitalism perhaps the same ones despised by William $\mathrm{H}$. Jordy - that housed a growing service industry of shopping, eating and entertainment. xxviii For Roelstraete, on the other hand, the photorealists depicted the dignity of service industry workers and celebrated their places of labour in a kind of 1970s Socialist Realism, finding deep authenticity in the fleeting surfaces of the capitalist landscape. ${ }^{x x i x}$

Roelstraete reminds us of Greenberg's early 1960s speculation on flatness as an essential quality of modernist painting ${ }^{\mathrm{xx}}$ and provides useful concepts for exploring the qualities and meanings of shiny reflective surfaces. He notes the importance to the photorealists of the instability of shiny surfaces rendered in paint, both their actual instability - as light shifts, reflections change - and the sensorial instability that these qualities induce. In doing so, he points towards aspects of the paradoxical character of shininess. The photorealists' renderings of shop windows simultaneously invite and repel with a 'confusion of opacity and transparency, or "inside" and "outside"'. xxxi When considering their relevance in modern consumption, it is the disembodied strangeness of shiny surfaces, their de-stabilising qualities that 'render all questions of both origin and substance oddly irrelevant' ${ }^{\text {xxxii }}$.

\section{The Articles}

The contrasting meanings of shininess are evidenced in both the shimmering celebration of American capitalism found in Roelstraete's photorealists, and in Tijana Vujosevic's gleaming 
Moscow Metro. In her article, 'Soviet Modernity and the Aesthetics of Gleam: The Moscow Metro in Collective Histories of Construction', Vujosevic dissects the celebratory rhetoric surrounding the construction of the Moscow Metro in the 1930s. Unearthed are the enthusiastic voices of workers who experienced the palatial marbled station halls and the 'speed, sudden flashes, [and] blindness' of the shining nickel-plated trains. Vujosevic explores the written celebrations describing the dizzying experiences of modernity as a 'gloss over' harsh lived realities. The article illustrates the experience of modernity articulated by Marshall Berman, 'To be modern is to live a life of paradox and contradiction'. ${ }^{x x x i i i}$ The Soviet Metro is revealed to be a luminous and incongruous expression of collective modernity: a great aesthetic and propagandistic triumph, a moderate technological success and a monumental social failure.

Nicolas P Maffei's article, 'Selling Gleam: Making Steel Modern in Post-war America' interrogates the American steel industry and its use of the rhetoric and imagery of shine to rebrand itself as modern. In advertising, logo and retail design shine was used to suggest a range of modern qualities, including progressiveness, novelty, and technological innovation. Here Habermas's notion of modernity as progressive, always accelerating and advancing, while fleeing the past and seeking the future, can be seen as the heart of post-war branding and consumerism in general and central to the post-war image of big steel in particular. Through this repositioning of the steel industry it was hoped that the next generation of customers would see steel in a new way: not as a dark, heavy, trade of girders and iron, but as high tech, innovative, and stylish. However, this modern approach had to endure the postmodern realities of global competition, not to mention Banham's knowing consumers who surely resented being sold a shiny facade that masked a slow-moving and conservative industrial giant. Or worse, these new consumers might find more pleasure in consuming a shiny steel substitute, typified by Banham's gleaming plastic car trim. 
It is the gleam of plastic surfaces that is the focus of Tom Fisher's article. The 'bright shining surfaces' that post-war consumers were promised that plastics would make possible are another instance of the democratised shine that Banham outlined, ${ }^{x x i v}$ manifested in the unspectacular everyday domestic environment. The meanings that accrued to the materials mixed excitement, confusion and distrust. They were characterised through narratives of progressive technology that co-existed with suspicions about their authenticity. They were both modern, and a vehicle for modernism. As consumers gained direct experience of the materials in their homes and witnessed their gleam turning to dross, progressive associations became strongly tempered by suspicions that centred round plastics' ecological consequences. For all that they had lost their metaphoric 'gloss' by the 1970s, plastics did offer novel physical properties, among which the qualities of their surfaces were particularly potent for their modernity. A transparent plastic hair-brush has a shimmering quality that was not possible in any other material, which challenged assumptions about the stability of objects.

In the light of Roelstraete's observation that shiny surfaces 'render [...] questions of both origin and substance oddly irrelevant' the novelty of such objects seems to exist in their lack of stability, their disembodied strangeness. ${ }^{x x v}$ The account that Sabine Hielsher gives of women's interactions with hair products over the twentieth century describes the never-ending battle between 'good shine' and 'bad shine' that is the consequence of those products' action. They promise to replace the body's dubious products - unpleasant because 'slimy' in Sartre's sense - with shine that is somehow sanctified by the consumption of hair-care products. The reliance on processes of caring for the body links this account with the work required to care for shine in other contexts, discussed above. The distinctive features of this process, this 'hair-care project', rest in the relationship that the relatively 'depthless' shine of hair has with consumerist self-presentation and identity. Success in this project requires that women reconcile the opposing forces of grease and detergent to produce a result that resembles the immanent shine of 
health. But perhaps a woman with perfect, shining, hair is more image than person.

\section{The play of light: unstable surfaces and meanings}

Our experience of everyday objects can convince us that we live in a world made up of stable materials: surfaces appear hard; structures seem permanent; our perception feels authentic. This Special Issue, however, proposes that the fugitive nature of shininess reveals the instability of both the appearance and experience of things: light, surface and perception act in concert as both, betraying objects' physicality and their cultural significance..

Shine is a consequence of a multitude of lighting conditions and surfaces - its varieties are innumerable. Activated by the play of light, its effects range from dazzling gloss to lustrous matt played out on diverse surfaces, from aged and pitted aluminium building panels to buffed and polished leather. Both elusive and allusive, the contingent nature of shininess refuses to be pinned down. It can be associated with bodily health (physical glow); pride in labour (boot shine); rarity, wealth and high status (the immanent gleam of gold); or the common, cheap and temporary (the glaring tide of disposable goods). Just as its diversity is evident in many examples across time, space and culture, it can be approached through various frames of analysis, whether pre-modern, modern or postmodern. As these historical frames alter interpretation, shininess shows its instability as a carrier of meaning.

While the shine of aluminium, stainless steel and Vitrolite suggest rational values, which are historically determined, we also have more direct relationships to shine. On a visceral level it can repel and disgust - the sheen that suggests decay or the oozing breakdown of bodily containment starkly contrasts with the values of hygiene, order and mechanical function associated with modernist shine. The radiance of numinous mystery in a devotional space or the easy attraction of the shiny surfaces of consumerism. [THIS IS NOW A POINT ABOUT 'TOUCH AND SENSES' VS CULTURAL CATEGORIES - 


\section{PERHAPS A FINAL SENTENCE TO NOTE THAT SHININESS ENCAPSULATES BOTH POLES OF THIS?]}

\footnotetext{
'Rowlands describes the value put on oiled and shiny skin as a sign of health associated with personal worth among West Africans, 'Skin that is dry and flaky is a sign of ill health, of old age and approaching death.' ( $p$. 161) The body is presented as a 'highly polished machine.' 'The Material Culture of Success: Ideals and Life Cycles in Cameroon', in J. Friedman (ed.) Consumption and Identity, Routledge, London, 1994, pp. 147-167, p. 162.

ii J-P. Sartre, Being and Nothingness: an Essay on Phenomenological Ontology, Methuen, London, 1957 (1943).

iii C. Biggam, 'The Ambiguity of Brightness (with special reference to Old English) and a new model for color description in semantics,' Anthropology of Color: Interdisciplinary Multilevel Modeling, R. E. Maclaury, G. V. Paramei, D. Dedrick, (ed.s), John Benjamin Publishing Company, Amsterdam, 2007, pp. 171-188, p. 183.

iv M. McGinn, 'Wittgenstein's Remarks on Colour', Philosophy, vol. 66, no. 258, pp. 435-354

v J. Tanizaki, In Praise of Shadows, Jonathan Cape, London, 1991, pp. 18, 20.

vi Tanizaki, pp. 46-47. Grant McCracken Culture and Consumption: new approaches to the symbolic character of consumer goods and activities, Indiana University Press, Bloomington, 1988, pp. 31-43, p. 32.

vii Grant McCracken Culture and Consumption: new approaches to the symbolic character of consumer goods and activities, Indiana University Press, Bloomington, 1988, pp. 31-43, p. 32 and p36. For McCracken, this means that the symbolism of a patinated object works not as a Saussurean sign, but as a Peircean 'icon' directly demonstrating the age of an item, and hence verifying the length of time it has been possessed and its owner's status.

viii Though some patina - on leather for instance - results from the maintenance of a shiny surface.

${ }^{i x}$ C. Baudelaire, The painter of modern life Selected writings on art and artists, Penguin, Harmondsworth, 1972 (1848).

x P. Osborne, 'Modernity', A Dictionary of Cultural and Critical Theory, M. Payne, (ed.), Blackwell, Oxford, 1996.

xi J. Habermas, The Philosophical Discourse of Modernity, MIT Press, Cambridge, Mass., 1987, p. 6.

xii M. Berman, All That is Solid Melts into Air: The Experience of Modernity, Simon and Schuster, New York, 1982, p. 157.

xiii M. Bille and T. F. Sorensen, 'An Anthropology of Luminosity: the Agency of Light', Journal of Material Culture, vol. 12 , no. 3, 2007, pp. 263-284.

xiv Ibid., p. 266.

${ }^{x v}$ G. McCracken, p. 86; see also R. Belk 'Possessions and the Extended Self', in D. Miller (ed.), Consumption: Critical Concepts in the Social Sciences, Routledge, London, 2001.

${ }^{x v i}$ C. Rice, 'On Historical versus Material Objects, or, What It Means to Care Rather Than Simply to Clean', Interiors, Berg, London, vol. 1, no.s 1-2, pp. 19-28, p. 26, 2010.

xvii This relationship between shininess and social affairs appears in Marcia Pointon's work on brilliant things of great value, where she uses Thorstein Veblen, Georg Simmel and Pierre Bourdieu to explore the socioeconomic extremes at which shininess connotes value. Just as the shiny work boots that Rice describes beam with working class pride, precious jewels radiate conspicuous leisure
}

M. Pointon, Brilliant Effects: A Cultural History of Gem Stones and Jewellery, Yale University Press, New Haven, 2009. 
xviii C. Edwards, 'Aluminium Furniture, 1886-1986: The Changing Applications and Reception of a Modern Material', The Journal of Design History, vol. 14, no. 3, 2001, pp. 207-225.

${ }^{x i x}$ R. J. S. Gutman, 'Diner Design: Overlooked Sophistication', Perspecta, Yale School of Architecture, New Haven, CT, no. 15, 1975, pp. 41-53.

${ }^{\mathrm{xx}} \mathrm{H}$. W. Jandl, 'With Heritage So Shiny: America's First All-Aluminum House', APT Bulletin, Association for Preservation Technology, Ottawa, vol. 23, no. 2, 1991, pp. 38-43, p. 38.

xxi Ibid., p. 42.

xxii R. Banham, The Aspen Papers: Twenty Years of Design Theory from the International Design Conference in Aspen, Pall Mall, London, 1974, p. 156.

xxiii W. H. Jordy, 'Humanism in Contemporary Architecture: Tough- and Tender-Minded', Journal of Architectural Education, Blackwell Publishing, vol. 15, no. 2, Summer, 1960, pp. 3-10, p. 6.

xxiv Banham, p. 159.

xxv Ibid., p. 7.

${ }^{x x v i}$ D. Roelstraete, 'Modernism, Postmodernism and Gleam: On the Photorealist Work Ethic', Afterall: A Journal of Art, Context, and Enquiry, University of Chicago Press, no. 24, Summer, 2010, pp. 5-15. See for example the exhibition Shiny, 2006, Wexner Center, which included numerous pieces of gleaming art, such as Andy Warhol's floating, helium-filled Silver Clouds and Jeff Koons's 10-foot-tall, stainless steel Balloon Dog. http://wexarts.org/exhibitions/shiny. On the 'ungraspable opacity' and 'pure lucidity' of the contents of the show, see Stephen Melville, '“Twice Untitled' and Other Shows', Journal of Visual Culture, Sage, London, vol. 8, no. 103, 2009, p. 113.

xxvii Roelstraete, p. 6.

xxviii Ibid, pp. 7-8; F. Jameson, Postmodernism, Or the Cultural Logic of Late Capitalism, Duke University Press, Durham, NC, 1991.

${ }^{x x i x}$ Roelstraete, pp. 6, 8.

${ }^{x x x}$ C. Greenberg, 'Modernist Painting', Art and Literature, no. 4, Spring, 1965, pp. 193-201

${ }^{x x x i}$ Roelstraete $p^{*}$

xxxii Ibid., p*

xxxiii Berman, p. 13.

xxxiv Banham, p. 156

${ }^{x x x v}$ Roelstraete p. ${ }^{*}$ 